\title{
Developments in MRI-targeted prostate biopsy
}

Joseph M. Norris, ${ }^{1,2,3}$ Adam Kinnaird, ${ }^{4}$ Daniel J. Margolis, ${ }^{5}$ Anwar R. Padhani, ${ }^{6}$ Jochen Walz, ${ }^{7}$ Veeru Kasivisvanathan ${ }^{1,3,8}$

${ }^{1}$ UCL Division of Surgery and Interventional Science, University College London, London, UK

${ }^{2}$ London Deanery of Urology, London, UK

${ }^{3}$ Department of Urology, University College London Hospitals NHS Foundation Trust, London, UK

${ }^{4}$ Department of Urology, University of California, Los Angeles, Los Angeles, CA, USA

${ }^{5}$ Department of Radiology, Weill-Cornell Medical College, NY, USA

${ }^{6}$ Paul Strickland Scanner Centre, Mount Vernon Cancer Centre, Northwood, UK

${ }^{7}$ Department of Urology, Institut Paoli-Calmettes Cancer Centre, Marseille, France

${ }^{8}$ Department of Urology, Frimley Health NHS Foundation Trust, London, UK

\section{Correspondence to: $\quad$ Mr Joseph M Norris}

BSc (Hons), MSc, BM BS, MRCS (Eng)

MRC Clinical Research Training Fellow, University College London

UCL Division of Surgery \& Interventional Science, $3^{\text {rd }}$ Floor, Charles Bell House, London, UK, W1W 7TS

Email: joseph.norris@ucl.ac.uk

Phone: +447724022171

ORCID: 0000-0003-2294-0303

Article type: Narrative review article.

Conflicts of interest: Veeru Kasivisvanathan and Jochen Walz haveas received speaker fees from the European Association of Urology for teaching on prostate cancer diagnosis.

Word count: 2,500231 words

Keywords: Biparametric MRI, fusion biopsy, multiparametric MRI, prostate cancer, targeted biopsy.

Ethics: Not required.

Funding: Joseph M. Norris is funded by the Medical Research Council (MRC) on an MRC Clinical Research Training Fellowship (MRC Grant Ref: MR/S00680X/1).

Abbreviations: bpMRI, biparametric magnetic resonance imaging; mpMRI, multiparametric magnetic resonance imaging; MRI-TB, MRI target biopsy; PI-RADS, Prostate Imaging Reporting and Data System; PSA, prostate specific antigen; START, Standards of Reporting for MRI-targeted Biopsy Studies; TRUS, transrectal ultrasound. 


\section{ABSTRACT}

\section{Purpose of review}

Magnetic resonance imaging (MRI)-targeted prostate biopsy may be an attractive alternative to systematic biopsy for diagnosing clinically significant prostate cancer. In this narrative review, we discuss the new developments that have occurred in the advancement of MRI-targeted prostate biopsy, over the past 24 months.

\section{Recent findings}

MRI-targeted biopsy offers enhanced diagnostic accuracy, when compared to the current standard of care of systematic transrectal ultrasound guided (TRUS)-biopsy, by decreasing the overall number of biopsies needed, maintaining or improving significant prostate cancer detection, and reducing the detection of clinically insignificant prostate cancer. The necessity of combining systematic prostate biopsy with MRI-targeted biopsy is still debated. The use of MRI-ultrasound fusion systems for lesion-targeting is promising for optimising significant cancer detection, but recent evidence suggests that additional cognitive biopsy is-cores are still useful in detecting additional cancers. Finally, incorporation of biparametric MRI and machine learning systems are key areas for future research.

\section{Summary}

MRI-targeted biopsy in selected men with positive MRI offers a number of benefits over traditional-systematic TRUS-biopsy in all men, and as such, may emerge as the new standard of care for the diagnosis of clinically significant prostate cancer.

\section{Keywords}

biparametric MRI, Ffusion biopsy, multiparametric MRI, prostate cancer, targeted biopsy, focal saturation

\section{KEY POINTS}

- IARI-targeted biopsy in MRI selected men may be-may be an attractive alternative to elassical-systematic TRUS-biopsy in all men.

- MRI-targeted biopsy maintains or improves significant prostate cancer detection compared to systematic transroctal ultrasound guided biopsy.

- MRI-ultrasound fusion may enhance the accuracy of targeted biopsy.

- It is still debated whether systematic biopsy can be omitted when performing targeted biopsy.

- The number of biopsy cores per MRI lesion requires further elucidation. 


\section{INTRODUCTION}

Multiparametric magnetic resonance imaging (mpMRI) has become an increasingly important element of the prostate cancer diagnostic pathway, enabling enhanced risk stratification compared to traditional approaches, such as systematic transrectal ultrasound (TRUS)-guided prostate biopsy. ${ }^{1-13}$ MRI-targeted biopsy (MRI-TB) is where the conduct of a biopsy is influenced by knowledge of where suspicious areas are on a prior MRI scan, and biopsy cores are directed only at the MRI-suspicious areas_figure 1). Potential advantages of MRI-TB include increasing rates of detection of clinically significant prostate cancer, decreasing the number of required biopsies, and reducing detection and treatment of clinically insignificant prostate cancer. ${ }^{13-18} \underline{\text { Recent publications }}$ of high quality of evidence compliant with the Standards of Reporting for MRI-targeted Biopsy (START) guidance [ref], have enabled MRI-TB to be incorporated into national and international clinical guidelines for prostate cancer diagnosis in biopsy naïve and prior negative biopsy menPrevious studies evaluating MRI-TB were limited in quality, however, since publication of the Standards of Reporting for MRI-targeted Biopsy Studies (START), the quality of evidence has increased to such a level that MRI-TB is now included in national and international guidelines, and the Prostate Imaging Reporting and Data System (PI-RADS) Committee Biopsy Pathway. ${ }^{11,8,19-22}$ The aim of this review is to highlight the most important recent developments that have occurred with MRI-TB, and to consider key areas for future research.

Figure 1. MRI-targeted biopsy using MRI/fusion US platforms. A: mpMRI identifying lesion. B: Contouring of lesion on MRI. C: Image registration on real-time US. D: Biopsy needle in lesion on real-time US. 


\section{MRI-TB vs. SYSTEMATIC BIOPSY}

Whether MRI-TB confers true benefit over traditional systematic prostate biopsy in biopsy naïve men is arguably the most fundamental question asked of the new, MRI-directed diagnostic pathway. Fortunately, during the past two years, several high-quality clinical trials have contributed to settlingclarified this debate.

Three studies have recently addressed this question in biopsy-naïve men with suspected prostate cancer. In the MRI-FIRST trial, Rouvière and colleagues conducted a prospective, multicentre, paired diagnostic study across 16 French centres, comparing the utility of MRI-TB to 12-core systematic biopsy, when both are performed within the same patient. ${ }^{23}$ They found that detection of clinically significant prostate cancer (defined as Grade Group $\geq 2$ ) was higher withwere similar with MRI-TB than withand systematic biopsy $(32.3 \%$ vs. $3029.9 \%, p=0.38)$ but was highest when the two techniques were combined. In a parallel approach, in the $4 \mathrm{M}$ study, van der Leest and colleagues delivered a prospective, multicentre, comparative effectiveness trial in which MRI-TB was compared to systematic TRUS-biopsy (in the same patient). ${ }^{24}$ Despite $49 \%$ of men having a negative MRI, the detection of clinically significant prostate cancer between MRI-TB and systematic biopsy ( $25 \%$ vs. $23 \%, p=0.17$, respectively) was very similar. Only $3 \%$ of men in the MRI-negative group had clinically significant cancer detected by systematic TRUS-biopsy. This study highlights the large number of men who could benefit from avoiding biopsy if an MRI was used as a triage test to avoid biopsy. An additionally important finding from the $4 \mathrm{M}$ trial is that MRI-TB detects less clinically insignificant cancer than systematic biopsy (14\% vs. $25 \%$, p $\leq 0.0001$, which has clear ramifications for reducing overdetection and overtreatme. At. Lastly, PRECISION was a multicentre, randomised, noninferiority trial in which men with suspected prostate cancer were randomised to either traditional systematic TRUSbiopsy or MRI-TB. ${ }^{1}$ In reiteration of Unlike the findings of the MRI-FIRST and 4M trials, PRECISION demonstrated that MRI-TB detected a higher proportion of clinically significant prostate cancer $(38 \%$ vs $26 \%, p=0.005)$ and a lower proportion of clinically insignificant cancer (9\% vs $22 \%$ ) than systematic biopsy. Indeed, 71 men (28\%) of men in the MRI-TB arm avoided biopsy altogether, due to non-suspicious pre-biopsy mpMRI. The headline results from these trials have been confirmed by recent publication of two four systematic reviews with meta-analyses. ${ }^{19,25-27}$ These meta-analyses confirmed the superiority of MRI-TB over systematic biopsy in both biopsy naïve men and those with a prior negative TRUS biopsy. As a result of these studies, mpMRI and MRI-TB have been included in the most recent EAU and NICE guidelines.e, These-in which they advise MRI-TB in cases of suspicious pre-biopsy mpMRI

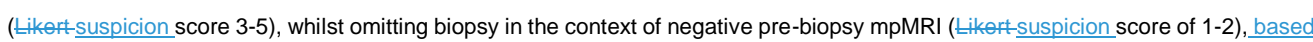
on shared decision making with the patient, thereby maximising significant disease detection in the most cost-effective manner. ${ }^{20,2+}$ The two guidelines do differ as to which reporting scheme they recommend - the EAU guidelines recommend the PI-RADS system for acquisition and interpretation of mpMRI, whilst the NICE guidelines advise use of a Likert approach. ${ }^{20,21}$

However, we have not yet seen these results recapitulated in the active surveillance population. In ASIST, Klotz and colleagues took a cohort of men with recent Grade Group 1 prostate cancer (diagnosed on systematic biopsy) and randomised them to either 12 core systematic biopsy or to MRI-TB, to assess for proportion of upgrade to Grade Group $\geq 2 .{ }^{28} \varepsilon$ In contrast to the primary diagnostic cohorts, only $14 \%$ of patients in the MRI-TB arm had disease stage upgrade on re-biopsy, compared with $23 \%$ of patients in the systematic biopsy arm $(p=0.09)$. RA recogniseded limitations of this study was-were the different populations and the learning curve 
in MRI and MRI-TB at the participating institutions, which highlights that an-the success of the MRI-TB approach is dependent on disease prevalence, high-quality MRI, interpretation and the skills of skilled operators in performing MRI-TB. 
Table 1. Summary of recent key studies comparing MRI-TB and systematic biopsy for clinically significant prostate cancer detection

\begin{tabular}{|c|c|c|c|c|c|c|c|}
\hline First author, year & Centre, country & Trial name & Trial design & No. pts & Study population & Comparison & Key findings \\
\hline Rouvière, $2019^{23}$ & Multiple, France & MRI-FIRST & Paired cohort & 275 & Biopsy-naïve men & MRI-TB vs. systematic TRUS-biopsy & $\begin{array}{l}\text { MRI-TB and systematic TRUS-biopsy detected similar rates of clinically } \\
\text { significant prostate cancer ( } 32.3 \% \text { vs. } 29.9 \%, p=0.38) .20 \% \text { of } \\
\text { clinically significant prostate cancer was detected by MRI-TB; } 14 \% \text { of } \\
\text { clinically significant prostate cancer was detected systematic TRUS- } \\
\text { biopsy only; however, maximal detection (66\%) was achieved when } \\
\text { both techniques were combined.these } 94 \text { patients were diagnosed by } \\
\text { systematic biopsy only, } 19(20 \%) \text { by targeted biopsy only, and } 62 \\
(66 \%) \text { by both techniques. Omission of systematic biopsy would have } \\
\text { resulted in the overlooking of } 5.2 \% \text { of clinically signnificant disease. }\end{array}$ \\
\hline van der Leest, $2019^{24}$ & Multiple, Netherlands & $4 \mathrm{M}$ & Paired cohort & 626 & Biopsy-naive men & MRI-TB vs. systematic TRUS-biopsy & $\begin{array}{l}\text { MRI-TB and systematic TRUS-biopsy detected similar rates of clinically } \\
\text { significant prostate cancer ( } 25 \% \text { vs. } 23 \%) \text {. However, MRI-TB detected } \\
\text { a lower proportion of clinically insignificant disease (14\% vs. } 25 \% \text { ). An } \\
\text { additional benefit of MRI-TB was reduced numbers of biopsied men } \\
\text { due to non-suspicious mpMRI. }\end{array}$ \\
\hline Kasivisvanathan, $2018^{1}$ & Multiple, International & PRECISON & $\mathrm{RCT}$ & 500 & Biopsy-naive men & MRI-TB vs. systematic TRUS-biopsy & $\begin{array}{l}\text { MRI-TB detected more clinically significant prostate cancer }(38 \%) \text { that } \\
\text { systematic TRUS-biopsy }(26 \% \text {; } p=0.005) \text {. Furthermore, MRI-TB } \\
\text { detected less clinically insignificant prostate cancer than systematic } \\
\left.\text { biopsy } \_9 \% \text { vs. } 22 \%, p<0.001\right)=\end{array}$ \\
\hline
\end{tabular}

MRI-TB, magnetic resonance imaging-target biopsy; no., number; pts, patients; RCT, randomised controlled trial; TRUS, transrectal ultrasound; vs., versus. 


\section{REGISTRATION METHODS}

The three predominant approaches to MRI-target registration for biopsy are: visual registration (cognitive registration, by mentally translating mpMRI targets onto real-time moving ultrasound images during the procedure), MRI/ultrasound-fusion registration, and in-bore MRI-targeted registration. ${ }^{297}$ It remains unclear as to which approach is superior, and the debate has been central to several recent clinical trials.

Wegelin and colleagues conducted a multicentre randomised controlled trial (FUTURE) of 665 men with prior negative systematic biopsy. ${ }^{3028}$ After mpMRI, all men were randomised to one of the three registration approaches. They assessed detection of all cancer, and clinically significant cancer, between each of the approaches, and interestingly, they found no statistically significant difference between any registration techniques, however this trial did suffer from being statistically underpowered. In another study, Hamid and colleagues compared cognitive registration to MRI-ultrasound fusion (using the SmartTarget Biopsy system), with a blinded, withinperson randomised, paired validating study design (SMARTTARGET). ${ }^{329}$ Both registration strategies detected $86 \%$ of the overal present clinically significant prostate cancer, when analysed individually; however, when the two techniques (cognitive and fusion) were combined they found a $14 \%$ improvement in detection rate, suggesting benefits of a combined approach, when technologicallyfeasible. It is thus important that when operators use a fusion system, they do not simply rely on the location of the lesion displayed by the operating fusion system, but also use their own judgment as they would in a visual registration technique.

Elkhoury et al. also conducted a three-technique comparison, this time comparing cognitive biopsy, MRI-US fusion biopsy, and systematic biopsy (PAIREDCAP). ${ }^{32}$ Each patient underwent all of three techniques. Rates of detected cancer varied from $47 \%$ when using cognitive fusion biopsy alone, to approximately $60 \%$ when using systematic biopsy or either fusion method, to $70 \%$ when combining systematic and targeted biopsies. They concluded therefore that the highest rate of cancer detection was achieved through combining systematic and MRI-TB. In parallel to Hamid et al., they found that the locations for detected tumours varied depending on which registration method was used, suggesting that each technique might detect a different tumour population. One importan consideration for the PAIREDCAP trial is the high prevalence of ISUP grade $\geq 2$ cancers (61\%) in biopsy-naïve men detected by a combined approach of MRI-targeted and systematic biopsies. This overall 61\% (182/300 men) prevalence resulted in a $70 \%$ (174/ 248 men) ISUP grade $\geq 2$ detection rate in men with a positive MRI scan, with a marginal non-significant added benefit of targeted biopsies; the detection rates for targeted biopsy and systematic biopsy were 62\% (154/248) and 60\% $(149 / 248)(p=0.70)$, respectively. In comparison, the pooled prevalence in biopsy-naïve men was $28 \%$ in the Cochrane meta-analysis. This $28 \%(95 \%$ Cl: $24-33 \%)$ prevalence resulted in a $44 \%(95 \% \mathrm{Cl}: 39-50 \%)$ ISUP grade $\geq 2$ detection rate in men with a positive MRI scan with a significant added benefit of targeted biopsies; the detection rates for targeted biopsy and systematic biopsy were $39 \%(95 \% \mathrm{Cl}: 33$ $46 \%)$ and $34 \%(95 \% \mathrm{Cl}: 28-41 \%)(p=0.03)$, respectively. Therefore, when there is a very high risk of clinically significant prostate cancer, the benefit of a positive MRI decreases in comparison to a lower but elevated risk.

Finally, the PICTURE trial evaluated the diagnostic accuracy of cognitive and fusion techniques, using transperineal template mapping biopsy as the reference standard. ${ }^{3337}$ As with PROMIS, the UCL definition 1 (Gleason $4+3$ or greater and/or any grade of cancer with a length of at least $6 \mathrm{~mm}$ ) was used to define clinically significant prostate cancer. The authors found similar levels of 
clinically significant prostate cancer were detected, regardless of which registration method was used ( $31 \%$ for cognitive; $28 \%$ for fusion). Their conclusion, as seems to be a theme with some of the other trials, was that detection was maximised when the two approaches are combined. 


\begin{tabular}{|c|c|c|c|c|c|c|c|}
\hline First author, year & Centre, country & Trial name & Trial design & No. pts & Study population & Registration method & Key findings \\
\hline Wegelin, 20199028 & Multiple, Netherlands & FUTURE & RCT & 665 & Prev. negative biopsy & Cognitive vs. US-fusion vs. in-bore & $\begin{array}{l}\text { There were no significant differences in the detection } \\
\text { rates of csPCa between each of the registration } \\
\text { approaches (fusion } 34 \% \text {, cognitive } 33 \% \text {, in-bore } \\
33 \% ; p>0.9 \text { ). }\end{array}$ \\
\hline Hamid, 2019 & UCL, UK & SMARTTARGET & Paired cohort & 141 & Prev. negative or positive biopsy & Cognitive vs. US-fusion (SmartTarget) & $\begin{array}{l}\text { Similar levels of csPCa detected by each method } \\
\text { ( } 86 \% \text { each); however, detection was maximised } \\
\text { when the two approaches are combined. } \\
\text { Interestingly, the cases missed by one technique } \\
\text { were detected by the other. }\end{array}$ \\
\hline Elkhoury, 2019320 & UCLA, USA & PAIREDCAP & Paired cohort & 300 & Biopsy-naive men & Cognitive vs. US-fusion (Artemis) & $\begin{array}{l}\text { Cancer detection rates were lower for cognitive } \\
\text { biopsy }(47 \%) \text { than for fusion biopsy }(62 \%) \text { or for } \\
\text { systematic biopsy }(60 \%) \text {. Highest levels of detection } \\
\text { were achieved when MRI-TB was combined with } \\
\text { systematic biopsy }(70 \%) \text {. Tumour locations varied } \\
\text { between biopsy techniques suggest each technique } \\
\text { may detect different types of tumours. }\end{array}$ \\
\hline Simmons, $2018^{334}$ & UCL, UK & PICTURE & Paired cohort & 249 & Prev. TRUS biopsy & Cognitive vs. US-fusion (SmartTarget) & $\begin{array}{l}\text { Similar levels of csPCa detected by each method } \\
(31 \% \text { for cognitive; } 28 \% \text { for fusion); however, } \\
\text { detection was maximised when the two approaches } \\
\text { are combined. }\end{array}$ \\
\hline
\end{tabular}

csPCa, clinically significant prostate cancer; MRI, magnetic resonance imaging; no., number; pts, patients; prev., previous; UCL, University College London; UK, United Kingdom; US, ultrasound; USA, United States of America; vs., versus. 
Figure 1. MRI-targeted biopsy using MRI/fusion US platforms. A: mpMRI identifying lesion. B: Contouring of lesion on MRI.C: Image registration on real-ime US. D: Biopsy needle in lesion on real-ime US.

TOBE CONFIRMED 


\section{NUMBER OF BIOPSY CORES REQUIRED PER MRI LESION}

At present, there remains a lack of consensus regarding the required biopsy density (number of cores needed, per lesion) when performing MRI-TB. Biopsy protocols vary between centre, and the number of cores taken ranges anywhere from one to nine, per

lesion. ${ }^{342} \mathrm{~A}$ balance must be made between procedural complications, cost, maximal detection of clinically significant disease, and minimal detection of clinically insignificant disease - but, as yet, the optimal biopsy number is as unknown. Furthermore, it appears that failure to detect clinically significant prostate cancer after positive pre-biopsy MRI can be attributed to targeting errors. This is evidenced by detection of clinically significant caner in adjacent sextants to established MRI targets, ${ }^{24,23,35,36}$ however, systematic sampling of sectors adjacent to MRI targets does not alter risk stratification in the majority of men.

Lu and colleagues recently assessed the yield of significant cancer (defined as Gleason score $\geq 3+4$ ) when five or fewer cores were taken from suspicious MRI-visible lesions. Their results differed by patient population type, but they concluded that overall, two cores per lesion was too few - by only taking two cores, they missed $16 \%$ of clinically significant cancers at first biopsy, $27 \%$ in prior negative, and $32 \%$ in active surveillance patients. ${ }^{373}$ Zhang and colleagues sequentially labelled each biopsy core individually (taken transrectally, from an MRI-defined lesion) and showed that the amount of clinically significant cancer (defined as Grade Group $\geq 2$ ) increased as more cores are added, albeit marginally (one to three: $6.4 \%$ increase; three to five: $2.4 \%$ increase). ${ }^{384}$ This finding was corroborated by Dimitroulis and colleagues, who retrospectively analysed a cohort of men who had two cores taken per lesion. They compared the yield of the first biopsy to that of the second, and found that the first biopsy detected $89 \%$ of prostate cancers, and that the second biopsy upgraded the Gleason score in $10 \%$ of cases. ${ }^{395}$ It seems then, that at present an MRI-defined lesion should have more than 2 cores taken to ensure maximal capture of clinical significant disease, though the upper limit is not clearly defined however, 5-6 cores per lesion is at present a pragmatic compromise. $.31,38,40,41$ In addition, this warrants patient, lesion, and prostatespecific adjustment as necessary, as recently suggested by the Cambridge group, and that operator experience may also play a

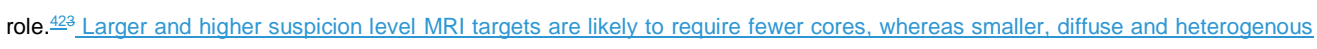
lesions should probably warrant a higher sampling density. 


\section{LEARNING CURVE IN MRI-TB}

Interpretation of mpMRI, including the detection and staging of prostate cancer is difficult, and is associated with a considerable learning curve. There is also a distinct learning curve for the performance of MRI-TB. It was shown that detection of cancer by MRITB improved from $27 \%$ to $63 \%$, over a two-year period of training, highlighting implications of high-quality training. recent studies confirmed this, showing that the learning curve over time is a key factor influencing detection of clinically significant prostate cancer at an individual and institutional level, 4438 and when assessed with various biopsy metrics, including of $\underline{\text { biopsy }}$ efficiency, accuracy ${ }^{4539}$ and content of fibromuscular tissue. 46,476

\section{The importance of the learning curve in MRI interpretation is further reinforced by the impact of expert reporting. The major benefits} of the, mpMRI pathway in biopsy naive men are the, reduction in, harm through decreasing numbers of biopsies performed, and by reduced detection of indolent cancer. Expert MRI readers are able to manifest these benefits by, reporting, higher rates of, normal and lower indeterminate cases. Furthermore, expert readers are able to report more consistently, with high levels of inter-reader concordance (weighted Cohen's $k \approx 0.7$ ), compared to less-experienced readers, especially when biparametric MRI (bpMRI), that lacks the contrast-enhancement sequence (sensitivity on bpMRI: 0.58 vs. $0.91, p<0.0001$ ) ${ }^{48}$ 


\section{KEY DEVELOPMENTS \& FUTURE DIRECTIONS}

The future of MRI-TB looks promising, with numerous emerging innovations. To overcome restrictions associated with contrastenhanced MRI (for example, complexity of image acquisition and interpretation, and associated costs) there has been a surge in interest in biparametric MRI (bpMRI) in which only two MRI sequences are required (T2-weighted and diffusion images). ${ }^{492}$ It is interesting to see that in single-centre studies, ${ }^{5043}$ multicentre trials ${ }^{5144,5245}$ and systematic reviews, ${ }^{5346}$ there appears to be very little difference in the diagnostic accuracy of bpMRI compared to mpMRI, which may be attributed to the relatively small role that contrastenhancement plays in the PI-RADS scoring framework $\frac{54}{47}$ The implication being then, that if MRI is made more accessible - MRITB may be more accessible. Challenges for the future of bpMRI include correct identification of patients that are unsuitable for bpMR (requiring full $\mathrm{mpMRI}$ ). There are certainly some lesions which are contrast-only enhancing, and contrast may play a role in identifying smaller lesions, anterior fibromuscular stromal lesions and cribriform pattern prostate cancer. It may be interesting to evaluate the role of contrast in an appropriately conducted large-scale study where the MRI is scored using a system where the findings from the contrast sequences can make a difference between performing a biopsy or not. In an attempt to address this challenge, van der Leest and colleagues recently conducted a prospective, multi-reader, head-to-head study in which they compared detection of prostate cancer in biopsy naïve men with monoplanar (fast bpMRI), triplanar non-contrast bpMRI, and standard mpMRI. $\cdot 548$ They found identical sensitivity for high-grade disease for all protocols (95\%; 95\% Cl: 91-97\%). Less encouragingly though, they did find that with fast bpMRI there was an increase in the number of indicated biopsies (approximately $2 \%$ more than the other protocols), biopsy-related costs, and an increase in overdetection of insignificant disease (approximately $1 \%$ ) indicating further work and careful consideration should be given before widespread adoption of bpMRI.

Moreover, the generalisability of this study was further limited by the increase in PI-RADS 3 lesions with fast bpMRI compared to mpMRI $(6.4 \%$ vs. $11.2 \%)$, representing an absolute increase of $4.8 \%$, or $75 \%$ relative increase. If this $75 \%$ relative increase was extrapolated to PROMIS, PRECISION, or MRI-FIRST, the result would be an absolute increase of PI-RADS 3 lesions by $16-21 \%$.

Interestingly however, focused developments in diffusion weighted sequences may be the first to impact clinical practice. Application of diffusion kurtosis (higher b-values compared with predicted values) appears to be effectively discriminate malignant from benigh tissue, however it appears unable to discriminate clinically significant prostate cancer or add utility beyond standard diffusion imaging. ${ }^{49}$ Diffusion tensor imaging techniques (including, restriction spectrum imaging) ${ }^{50}$-are further methods in which diffusion can signify presence of prostate cancer (up to Gleason score $3+4)^{51}$ and when combined with contrast-enhancement can increase sensitivity $97-100 \% .^{52}$ Lastly, hyperpolarised MRI is another novel technique in which $13 \mathrm{C}$-pyruvate is given intravenously, dramatically boosting the MRI signal. The technology is currently the subject of a clinical trial (NCT03687645) interrogating the utility of tumour metabolism as a biomarker. The results are awaited

Another exciting avenue of research is deep and machine learning, offering the possibility of automating mpMRI interpretation and lowering inter-observer variability. Assimilation of PSA density, contrast-enhancement, and apparent diffusion coefficient data has been shown to outperform experienced radiologists in the detection of Gleason grade 4 prostate cancer, when machine learning elassifiers were constructed, ${ }^{53}$ and these also appear to outperform PI-RADSV2 in independent validation cohorts. ${ }^{54}$ The promise of artificial intelligence is that the radiological workload will be streamlined, however, it is unlikely that these developments will ever replace experienced uroradiologists, and will more likely find place as an adjunctive aid. 


\section{CONCLUSION}

MRI-TB has emerged as a highly attractive option compared to traditional systematic biopsy. The main advantages appear to be in reducing the number of overall biopsies and reducing detection of clinically insignificant disease whilst maintaining or improving significant cancer detection. As such, it seems possible that we will see MRI-TB emerge as the new standard of care in prostate cancer diagnosis. However, effective uptake of MRI-TB will require a high-level of expertise in interpreting MRI, performing targeted biopsy, and upon high-quality biopsy hardware and software, which all continue to pose implementation challenges for the future. Future research will focus on optimising these techniques, and machine learning offers the exciting potential to help reduce the interreader variability seen.

Acknowledgements

The authors would like to thank Dr Timothy McClure for kindly providing the images used in figure 1. 


\section{REFERENCES AND RECOMMENDED READING}

Papers of particular interest, published within the period of review, have been highlighted as:

- of special interest

- of outstanding interest

1. Kasivisvanathan V, Rannikko AS, Borghi M, Panebianco V, Mynderse LA, Vaarala MH, Briganti A, Budäus L, Hellawell G, Hindley RG, Roobol MJ, Eggener S, Ghei M, Villers A, Bladou F, Villeirs GM, Virdi J, Boxler S, Robert G, Singh PB, Venderink W, Hadaschik BA, Ruffion A, Hu JC, Margolis D, Crouzet S, Klotz L, Taneja SS, Pinto P, Gill I, Allen C, Giganti F, Freeman A, Morris S, Punwani S, Williams NR, Brew-Graves C, Deeks J, Takwoingi Y, Emberton M, Moore CM; PRECISION Study Group Collaborators. MRI-targeted or standard biopsy for prostate-cancer diagnosis. N Engl J Med. 2018 May 10;378(19):1767-77.

Large, multicentre RCT demonstrating the benefits of offering biopsy-naïve men an MRI-TB when they have an MRI-visible lesion, over traditional systematic biopsy.

2. Ahmed HU, El-Shater Bosaily A, Brown LC, Gabe R, Kaplan R, Parmar MK, Collaco-Moraes Y, Ward K, Hindley RG, Freeman A, Kirkham AP, Oldroyd R, Parker C, Emberton M; PROMIS study group. Diagnostic accuracy of multiparametric MRI and TRUS biopsy in prostate cancer (PROMIS): a paired validating confirmatory study. Lancet. 2017 Feb 25:389(10071):815-22.

Level 1 evidence (multicentre, paired-cohort, confirmatory study) illustrating high level of diagnostic accuracy of mpMRI over TRUS-biopsy, by comparing prostate mpMRI and TRUS-guided prostate biopsy, against a reference standard of $5 \mathrm{~mm}$ template mapping biopsy.

3. Panebianco V, Barchetti G, Simone G, Del Monte M, Ciardi A, Grompone MD, Campa R, Indino EL, Barchetti F, Sciarra

A, Leonardo C, Gallucci M, Catalano C. Negative multiparametric magnetic resonance imaging for prostate cancer: what's next? Eur Urol. $2018 \mathrm{Jul} ; 74(1): 48-54$.

Observational study of 'negative MRI' revealing $95 \%$ freedom from clinically significant disease by four years when baseline mpMRI does not demonstrate visible suspicious lesion, justifying avoidance of biopsy in cases of non-suspicious MRI.

4. Radtke JP, Wiesenfarth M, Kesch C, Freitag MT, Alt CD, Celik K, Distler F, Roth W, Wieczorek K, Stock C, Duensing S, Roethke MC, Teber D, Schlemmer HP, Hohenfellner M, Bonekamp D, Hadaschik BA. Combined clinical parameters and multiparametric magnetic resonance imaging for advanced risk modeling of prostate cancer-patient-tailored risk stratification can reduce Unnecessary biopsies. Eur Urol. 2017 Dec;72(6):888-96.

5. Mehralivand S, Shih JH, Rais-Bahrami S, Oto A, Bednarova S, Nix JW, Thomas JV, Gordetsky JB, Gaur S, Harmon SA, Siddiqui MM, Merino MJ, Parnes HL, Wood BJ, Pinto PA, Choyke PL, Turkbey B. A Magnetic resonance imagingbased prediction model for prostate biopsy risk stratification. JAMA Oncol. 2018 May 1;4(5):678-85.

6.

Moldovan PC, Van den Broeck T, Sylvester R, Marconi L, Bellmunt J, van den Bergh RCN, Bolla M, Briers E, Cumberbatch MG, Fossati N, Gross T, Henry AM, Joniau S, van der Kwast TH, Matveev VB, van der Poel HG, De Santis M, Schoots IG, Wiegel T, Yuan CY, Cornford P, Mottet N, Lam TB, Rouvière O. What is the negative predictive value of multiparametric Magnetic Resonance Imaging in excluding prostate cancer at biopsy? A systematic review 
and meta-analysis from the European Association of Urology prostate cancer guidelines panel. Eur Urol. 2017 Aug;72(2):250-66.

7. Hamdy FC, Donovan JL, Lane JA, Mason M, Metcalfe C, Holding P, Davis M, Peters TJ, Turner EL, Martin RM, Oxley J, Robinson M, Staffurth J, Walsh E, Bollina P, Catto J, Doble A, Doherty A, Gillatt D, Kockelbergh R, Kynaston H, Paul A, Powell P, Prescott S, Rosario DJ, Rowe E, Neal DE; ProtecT Study Group. 10-year outcomes after monitoring surgery, or radiotherapy for localized prostate cancer. N Engl J Med. 2016 Oct 13;375(15):1415-24.

Long-term data illustrating no significant difference in prostate-cancer specific mortality between monitoring, surgery, or radiotherapy for localised prostate cancer, detected by PSA screening.

8. Moore CM, Kasivisvanathan V, Eggener S, Emberton M, Fütterer JJ, Gill IS, Grubb lii RL, Hadaschik B, Klotz L, Margolis DJ, Marks LS, Melamed J, Oto A, Palmer SL, Pinto P, Puech P, Punwani S, Rosenkrantz AB, Schoots IG, Simon R, Taneja SS, Turkbey B, Ukimura O, van der Meulen J, Villers A, Watanabe Y; START Consortium. Standards of reporting for MRI-targeted biopsy studies (START) of the prostate: recommendations from an International Working Group. Eur Urol. 2013 Oct;64(4):544-52. .

The authors gathered responses from a panel of experts to create a checklist of reporting criteria (the START checklist) to improve the quality of studies on MRI-TB.

9. Panebianco V, Barchetti F, Sciarra A, Ciardi A, Indino EL, Papalia R, Gallucci M, Tombolini V, Gentile V, Catalano C. Multiparametric magnetic resonance imaging vs. standard care in men being evaluated for prostate cancer: a randomized study. Urol Oncol. 2015 Jan;33(1):17.e1-17.e7.

10. Porpiglia F, Manfredi M, Mele F, Cossu M, Bollito E, Veltri A, Cirillo S, Regge D, Faletti R, Passera R, Fiori C, De Luca S. Diagnostic pathway with multiparametric magnetic resonance imaging versus standard pathway: results from a randomized prospective study in biopsy-naïve patients with suspected prostate cancer. Eur Urol. 2017 Aug;72(2):2828.

11. Moore CM, Robertson NL, Arsanious N, Middleton T, Villers A, Klotz L, Taneja SS, Emberton M. Image-guided prostate biopsy using magnetic resonance imaging-derived targets: a systematic review. Eur Urol. 2013 Jan;63(1):125-40.

12. Schoots IG, Nieboer D, Giganti F, Moore CM, Bangma CH, Roobol MJ. Is magnetic resonance imaging-targeted biopsy a useful addition to systematic confirmatory biopsy in men on active surveillance for low-risk prostate cancer? A systematic review and meta-analysis. BJU Int. 2018 Dec;122(6):946-58.

13. Sonn GA, Chang E, Natarajan S, Margolis DJ, Macairan M, Lieu P, Huang J, Dorey FJ, Reiter RE, Marks LS. Value of targeted prostate biopsy using magnetic resonance-ultrasound fusion in men with prior negative biopsy and elevated prostate-specific antigen. Eur Urol. 2014 Apr;65(4):809-15.

14. Valerio M, Donaldson I, Emberton M, Ehdaie B, Hadaschik BA, Marks LS, Mozer P, Rastinehad AR, Ahmed HU. Detection of clinically significant prostate cancer using magnetic resonance imaging-ultrasound fusion targeted biopsy: a systematic review. Eur Urol. $2015 \mathrm{Jul} ; 68(1): 8-19$.

15. Tonttila PP, Lantto J, Pääkkö E, Piippo U, Kauppila S, Lammentausta E, Ohtonen P, Vaarala MH. Prebiopsy multiparametric magnetic resonance imaging for prostate cancer diagnosis in biopsy-naive men with suspected 
prostate cancer based on elevated prostate-specific antigen values: results from a randomized prospective blinded controlled trial. Eur Urol. 2016 Mar;69(3):419-25.

16. Wilt TJ, Jones KM, Barry MJ, Andriole GL, Culkin D, Wheeler T, Aronson WJ, Brawer MK. Follow-up of prostatectomy versus observation for early prostate cancer. N Engl J Med. 2017 Jul 13;377(2):132-42.

17. Schröder FH, Hugosson J, Roobol MJ, Tammela TL, Ciatto S, Nelen V, Kwiatkowski M, Lujan M, Lilja H, Zappa M, Denis LJ, Recker F, Berenguer A, Määttänen L, Bangma CH, Aus G, Villers A, Rebillard X, van der Kwast T, Blijenberg BG, Moss SM, de Koning HJ, Auvinen A; ERSPC Investigators. Screening and prostate-cancer mortality in a randomized European study. N Engl J Med. 2009 Mar 26;360(13):1320-8.

18. Donovan JL, Hamdy FC, Lane JA, Mason M, Metcalfe C, Walsh E, Blazeby JM, Peters TJ, Holding P, Bonnington S, Lennon T, Bradshaw L, Cooper D, Herbert P, Howson J, Jones A, Lyons N, Salter E, Thompson P, Tidball S, Blaikie J, Gray C, Bollina P, Catto J, Doble A, Doherty A, Gillatt D, Kockelbergh R, Kynaston H, Paul A, Powell P, Prescott S, Rosario DJ, Rowe E, Davis M, Turner EL, Martin RM, Neal DE; ProtecT Study Group. Patient-reported outcomes after monitoring, surgery, or radiotherapy for prostate cancer. N Engl J Med. 2016 Oct 13;375(15):1425-37.

19. Kasivisvanathan V, Stabile A, Neves JB, Giganti F, Valerio M, Shanmugabavan Y, Clement KD, Sarkar D, Philippou Y, Thurtle D, Deeks J, Emberton M, Takwoingi Y, Moore CM. Magnetic resonance imaging-targeted biopsy versus systematic biopsy in the detection of prostate cancer: a systematic review and meta-analysis. Eur Urol. 2019 May 23.

Review comparing clinical trials that evaluated the diagnostic accuracy of MRI-TB. The authors showed that across the included studies, on the whole, MRI-TB detects more clinically significant prostate cancer, less clinically insignificant prostate cancer, and that the proportion of cores positive for cancer was greater for MRI-TB than for systematic biopsy.

20. Wise J. NICE recommends MRI for suspected prostate cancer to reduce biopsies. BMJ. 2018; 363:k5290.

21. Mottet N, van den Bergh RCN, Briers E et al. EAU Guidelines. https://uroweb.org/guidelines. Date: 2019.

22. Padhani AR, Barentsz J, Villeirs G, Rosenkrantz AB, Margolis DJ, Turkbey B, Thoeny HC, Cornud F, Haider MA, Macura KJ, Tempany CM, Verma S, Weinreb JC. PI-RADS steering committee: the PI-RADS multiparametric MRI and MRI-directed biopsy pathway. Radiology. 2019 Aug;292(2):464-74.

In this article, the PI-RADS steering committee discuss how the MRI pathway should be incorporated into clinical practice and the challenges in delivering this to with men suspected prostate cancer.

23. Rouvière $\mathrm{O}$, Puech $\mathrm{P}$, Renard-Penna R, Claudon M, Roy $\mathrm{C}$, Mège-Lechevallier $\mathrm{F}$, Decaussin-Petrucci M, DubreuilChambardel M, Magaud L, Remontet L, Ruffion A, Colombel M, Crouzet S, Schott AM, Lemaitre L, Rabilloud M, Grenier N13; MRI-FIRST Investigators. Use of prostate systematic and targeted biopsy on the basis of multiparametric MRI in biopsy-naive patients (MRI-FIRST): a prospective, multicentre, paired diagnostic study. Lancet Oncol. 2019 Jan;20(1):100-9.

Multicentre paired-diagnostic study in which biopsy-naïve men underwent 12-core systematic biopsy, followed by MRI-TB. They found that MRI-TB detected more clinically significant disease that systematic biopsy, however, they showed that yield was highest when the two approaches were combined. 
van der Leest M, Cornel E, Israël B, Hendriks R, Padhani AR, Hoogenboom M, Zamecnik P, Bakker D, Setiasti AY, Veltman J, van den Hout H, van der Lelij H, van Oort I, Klaver S, Debruyne F, Sedelaar M, Hannink G, Rovers M, Hulsbergen-van de Kaa C, Barentsz JO. Head-to-head comparison of transrectal ultrasound-guided prostate biopsy versus multiparametric prostate resonance imaging with subsequent magnetic resonance-guided biopsy in biopsynaïve men with elevated prostate-specific antigen: a large prospective multicenter clinical study. Eur Urol. 2019 Apr;75(4):570-8.

Large trial evaluating the traditional TRUS-guided diagnostic pathway to the new MRI-guided pathway in biopsy-naïve men. They did not detect differences in rates of detection of clinically significant disease, however it was found that MRI-TB detected lower levels of clinically insignificant prostate cancer.

25. Drost FH, Osses D, Nieboer D, Bangma CH, Steyerberg EW, Roobol MJ, Schoots IG. Prostate magnetic resonance imaging, with or without magnetic resonance imaging-targeted biopsy, and systematic biopsy for detecting prostate cancer: a Cochrane systematic review and meta-analysis. Eur Urol. 2019 Jul 17.

Formatted: Font: (Default) Helvetica, Font color: Auto

Cochrane review with accompanying meta-analysis comparing trials that evaluate MRI-TB compared to systematic biopsy, for the diagnosis of prostate cancer. The review concluded that MRI-TB detects higher levels of clinically significant prostate cancer, and lower levels of clinically insignificant prostate cancer.

26. Woo S, Suh $\mathrm{CH}$, Eastham JA, Zelefsky MJ, Morris MJ, Abida W, Scher HI, Sidlow R, Becker AS, Wibmer AG, Hricak H,

Vargas HA. Comparison of magnetic resonance imaging-stratified clinical pathways and systematic transrectal ultrasound-

guided biopsy pathway for the detection of clinically significant prostate cancer: a systematic review and meta-analysis of randomized controlled trials. Eur Urol Oncol. 2019 Jun 13.

27. Elwenspoek MMC, Sheppard AL, McInnes MDF, Merriel SWD, Rowe EWJ, Bryant RJ, Donovan JL, Whiting P. Comparison of multiparametric magnetic resonance imaging and targeted biopsy with systematic biopsy alone for the diagnosis of prostate cancer: a systematic review and meta-analysis. JAMA Netw Open. 2019 Aug 2;2(8):e198427.

26-28. Klotz L, Loblaw A, Sugar L, Moussa M, Berman DM, Van der Kwast T, Vesprini D, Milot L, Kebabdjian M, Fleshner N, Ghai S, Chin J, Pond GR, Haider M. Active surveillance magnetic resonance imaging study (ASIST): results of a randomized multicenter prospective trial. Eur Urol. 2019 Feb;75(2):300-9. .

Study designed to assess the impact of MRI-TB in upgrading men with low-grade cancer on active surveillance. The study showed that adding-in MRI-TB did not significantly improve the rate of disease upgrade in the active surveillance setting, beyond standard 12-core systematic biopsy.

27.29. Wegelin O, van Melick HH, Hooft L. Comparing three different techniques for magnetic resonance imaging-targeted prostate biopsies: a systematic review of in-bore versus magnetic resonance imaging-transrectal ultrasound fusion versus cognitive registration. Is there a preferred technique? Eur Urol. 2017;71:517-53.

28.30. Wegelin O, Exterkate L, van der Leest M, Kummer JA, Vreuls W, de Bruin PC, Bosch JLHR, Barentsz JO, Somford DM, van Melick HHE. The FUTURE trial: a multicenter randomised controlled trial on target biopsy techniques based on magnetic resonance imaging in the diagnosis of prostate cancer in patients with prior negative biopsies. Eur Urol. 2019 Apr;75(4):582-90. 
Multicenter randomised controlled trial in which men with previously negative prostate biopsies were randomised to the three MRI-TB registration approaches (cognitive, ultrasound-fusion, or in-bore). The authors found no significant differences in the detection rates of clinically significant prostate cancer between the three techniques.

29.31. Hamid S, Donaldson IA, Hu Y, Rodell R, Villarini B, Bonmati E, Tranter P, Punwani S, Sidhu HS, Willis S, van der Meulen J, Hawkes D, McCartan N, Potyka I, Williams NR, Brew-Graves C, Freeman A, Moore CM, Barratt D, Emberton M, Ahmed HU. The SmartTarget biopsy trial: a prospective, within-person randomised, blinded trial comparing the accuracy of visual-registration and magnetic resonance imaging/ultrasound image-fusion targeted biopsies for prostate cancer risk stratification. Eur Urol. 2019 May;75(5):733-40.

30.32. Elkhoury FF, Felker ER, Kwan L, Sisk AE, Delfin M, Natarajan S, Marks LS. Comparison of targeted vs systematic prostate biopsy in men who are biopsy naive: the prospective assessment of image registration in the diagnosis of prostate cancer (PAIREDCAP) study. JAMA Surg. 2019 Jun 12.

31.33. Simmons LAM, Kanthabalan A, Arya M, Briggs T, Barratt D, Charman SC, Freeman A, Hawkes D, Hu Y, Jameson C, McCartan N, Moore CM, Punwani S, van der Muelen J, Emberton M, Ahmed HU. Accuracy of transperineal targeted prostate biopsies, visual estimation and image fusion in men needing repeat biopsy in the PICTURE Trial. J Urol. 2018 Dec;200(6):1227-34

34. Valerio M, Donaldson I, Emberton M, Ehdaie B, Hadaschik BA, Marks LS, Mozer P, Rastinehad AR, Ahmed HU. Detection of clinically significant prostate cancer using magnetic resonance imaging-ultrasound fusion targeted biopsy: a systematic review. Eur Urol. $2015 \mathrm{Jul} ; 68(1): 8-19$

35. Bryk DJ, Llukani E, Taneja SS, Rosenkrantz AB, Huang WC, Lepor H. The role of ipsilateral and contralatera transrectal ultrasound-guided systematic prostate biopsy in men with unilateral magnetic resonance imaging lesion undergoing magnetic resonance imaging-ultrasound fusion-targeted prostate Bbopsy. Urology. 2017 Apr;102:178-2.

32.36. Muthigi A, George AK, Sidana A, Kongnyuy M, Simon R, Moreno V, Merino MJ, Choyke PL, Turkbey B, Wood BJ, Pinto PA. Missing the mark: prostate cancer upgrading by systematic biopsy over magnetic resonance imaging/transrectal ultrasound fusion biopsy. J Urol. 2017 Feb:197(2):327-34.

33.37. Lu AJ, Syed JS, Ghabili K, Hsiang WR, Nguyen KA, Leapman MS, Sprenkle PC. Role of core number and location in targeted magnetic resonance imaging-ultrasound fusion prostate biopsy. Eur Urol. 2019 Jul;76(1):14-7.

34.38. Zhang M, Milot L, Khalvati F, Sugar L, Downes M, Baig SM, Klotz L, Haider MA. Value of increasing biopsy cores per target with cognitive MRI-targeted transrectal US prostate biopsy. Radiology. 2019 Apr;291(1):83-9.

39. Dimitroulis P, Rabenalt R, Nini A, Hiester A, Esposito I, Schimmöller L, Antoch G, Albers P, Arsov C. Multiparametric magnetic resonance imaging/ultrasound fusion prostate biopsy-are 2 biopsy cores per magnetic resonance imaging lesion required? J Urol. 2018 Nov;200(5):1030-4.

40. Miah S, Servian P, Patel A, Lovegrove C, Skelton L, Shah TT, Eldred-Evans D, Arya M, Tam H, Ahmed HU, Winkler M.A prospective analysis of robotic targeted MRI-US fusion prostate biopsy using the centroid targeting approach. $J$ Robot Surg. 2019 Feb 19.

35.41. Calio BP, Sidana A, Sugano D, Gaur S, Maruf M, Jain AL, Merino MJ, Choyke PL, Wood BJ, Pinto PA, Turkbey B. Risk of upgrading from prostate biopsy to radical prostatectomy pathology-does saturation biopsy of index lesion during 
multiparametric magnetic resonance imaging-transrectal ultrasound fusion biopsy help? J Urol. 2018 Apr:199(4):976-

82.

36.42. Hansen NL, Barrett T, Lloyd T, Warren A, Samel C, Bratt O, Kastner C. Optimizing the number of cores for MRI guided targeted and systematic transperineal prostate biopsy. BJU Int. 2019 Jul 15.

37.43. Gaziev G1, Wadhwa K1, Barrett T2, Koo BC22, Gallagher FA2, Serrao E3,4, Frey J1, Seidenader J1, Carmona L1, Warren A5, Gnanapragasam V6, Doble A1, Kastner C1. Defining the learning curve for multiparametric magnetic resonance imaging (MRI) of the prostate using MRI-transrectal ultrasonography (TRUS) fusion-guided transperineal prostate biopsies as a validation tool. BJU Int. 2016 Jan;117(1):80-6.

38.44. Meng X, Rosenkrantz AB, Huang R, Deng FM, Wysock JS, Bjurlin MA, Huang WC, Lepor H, Taneja SS. The institutional learning curve of magnetic resonance imaging-ultrasound fusion targeted prostate biopsy: temporal improvements in cancer detection in 4 years. J Urol. 2018 Nov;200(5):1022-9.

39.45. Kasabwala K, Patel N, Cricco-Lizza E, Shimpi AA, Weng S, Buchmann RM, Motanagh S, Wu Y, Banerjee S, Khani F, Margolis DJ, Robinson BD, Hu JC. The learning curve for magnetic resonance imaging/ultrasound fusion-guided prostate biopsy. Eur Urol Oncol. 2019 Mar;2(2):135-40.

40. Halstuch D, Baniel J, Lifshitz D, Sela S, Ber Y, Margel D. Characterizing the learning curve of MRI-US fusion prostate biopsies. Prostate Cancer Prostatic Dis. 2019 Mar 6.

$\underline{46 .}$

41. Kasabwala K, Patel N, Cricco-Lizza E, Shimpi AA, Weng S, Buchmann RM, Motanagh S, Wu Y, Banerjee S, Khani F, Margolis DJ, Robinson BD, Hu JC. The learning curve for magnetic resonance imaging/ultrasound fusion-guided prostate biopsy. Eur Urol Oncol. 2019 Mar;2(2):135-40.

47.

48. Gatti M, Faletti R, Calleris G, Giglio J, Berzovini C, Gentile F, Marra G, Misischi F, Molinaro L, Bergamasco L, Gontero P. Papotti M, Fonio P. Prostate cancer detection with biparametric magnetic resonance imaging (bpMRI) by readers with different experience: performance and comparison with multiparametric (mpMRI). Abdom Radiol (NY). 2019 May;44(5):1883-93.

42.49. Emberton M. Dropping the GAD - just a fad? The case for a simpler, quicker, safer and cheaper prostate magnetic resonance imaging. BJU Int. 2019 Aug;124(2):183-4.

43.50. Fascelli M, Rais-Bahrami S, Sankineni S, Brown AM, George AK, Ho R, Frye T, Kilchevsky A, Chelluri R, Abboud S, Siddiqui MM, Merino MJ, Wood BJ, Choyke PL, Pinto PA, Turkbey B. Combined biparametric prostate magnetic resonance imaging and prostate-specific antigen in the detection of prostate cancer: a validation study in a biopsynaive patient population. Urology. 2016 Feb;88:125-34.

44.51. Boesen L, Nørgaard N, Løgager V, Balslev I, Bisbjerg R, Thestrup KC, Winther MD, Jakobsen H, Thomsen HS. Assessment of the diagnostic accuracy of biparametric magnetic resonance imaging for prostate cancer in biopsynaive men: the biparametric MRI for detection of prostate cancer (BIDOC) Study. JAMA Netw Open. 2018 Jun 1;1(2):e180219. 
Clinical trial designed to establish the diagnostic characteristic of bpMRI when used as a triage test. The authors found bpMRI to be highly accurate, with an NPV of $97 \%$ (95\% Cl, 95\%-99\%).

45-52. Jambor I, Verho J, Ettala O, Knaapila J, Taimen P, Syvänen KT, Kiviniemi A, Kähkönen E, Perez IM, Seppänen M, Rannikko A, Oksanen O, Riikonen J, Vimpeli SM, Kauko T, Merisaari H, Kallajoki M, Mirti T, Lamminen T, Saunavaara J, Aronen HJ, Boström PJ. Validation of IMPROD biparametric MRI in men with clinically suspected prostate cancer: a prospective multi-institutional trial. PLoS Med. 2019 Jun 3;16(6):e1002813.

46-53. Alabousi M, Salameh JP, Gusenbauer K, Samoilov L, Jafri A, Yu H, Alabousi A. Biparametric vs multiparametric prostate magnetic resonance imaging for the detection of prostate cancer in treatment-naïve patients: a diagnostic test accuracy systematic review and meta-analysis. BJU Int. 2019 Aug;124(2):209-20.

Review article comparing the diagnostic accuracy of mpMRI with bpMRI. Despite inherent study heterogeneity, the authors show no significant difference between the two MRI techniques.

47.54. Turkbey B, Rosenkrantz AB, Haider MA, Padhani AR, Villeirs G, Macura KJ, Tempany CM, Choyke PL, Cornud F, Margolis DJ, Thoeny HC, Verma S, Barentsz J, Weinreb JC. Prostate Imaging Reporting and Data System Version 2.1: 2019 update of Prostate Imaging Reporting and Data System Version 2. Eur Urol. 2019 Mar 18.

Latest edition of the PI-RADS prostate mpMRI reporting scheme, built from evidence in the literature and expert consensus. PIRADSv2.1 aims to address some of the limitations and ambiguities of PI-RADSv2.0.

48. van der Leest M, Israël B, Cornel EB, Zámecnik P, Schoots IG, van der Lelij H, Padhani AR, Rovers M, van Oort I, Sedelaar M, Hulsbergen-van de Kaa C, Hannink G, Veltman J, Barentsz J. High diagnostic performance of short magnetic resonance imaging protocols for prostate cancer detection in biopsy-naïve men: the next step in magnetic resonance imaging accessibility. Eur Urol. 2019 Jun 2.

49. Barrott T, MoLean M, Priest AN, Lawronce EM, Patterson AJ, Koo BC, Patterson I, Warron AY, Doble A, Gnanapragasam V, Kastner C, Gallagher FA. Diagnostic evaluation of magnetization transfer and diffusion kurtosis imaging for prostate cancer detection in a re-biopsy population. Eur Radiol. 2018 Aug;28(8):3141-50.

50. Felker ER, Raman SS, Shakeris, Mirak SA, Bajgiran AM, Kwan L, KhoshnoodiP, Elkhoury FF, Margolis DJA, Karow D, Lu DSK, White N, Marks LS. Utility of restriction spectrum imaging among men undergoing first-time biopsy for suspected prostate cancer. AJR Am J Roentgenol. 2019 Aug; $213(2): 365-70$.

51. Li L, Margolis DJ, Deng M, Cai J, Yuan L, Feng Z, Min X, Hu Z, Hu D, Liu J, Wang L. Correlation of Gleason scores with magnetic resonance diffusion tensor imaging in peripheral zone prostate tancer. J Alagn Reson Imaging. 2015 Aug; $42(2): 460-7$.

52. KozlowskiP, Chang SD, Meng R, Mädler B, Bell R, Jones EC, Goldenberg SL Combined prostate diffusion tensor imaging and dynamic contrast enhanced MRI at 3T-quantitative correlation with biopsy. Magn Reson Imaging. 2010 Jun;28(5):621-8.

53. Antonelli M, Johnston EW, Dikaios N, Cheung KK, Sidhu HS, Appayya MB, Giganti F, Simmons tAM, Freeman A, Allen C, Ahmed HU, Atkinson D, Ourselin S, PunwaniS. Machine learning elassifiers can predict Gleason pattern 4 prostate cancer with greater accuracy than experienced fadiologists. Eur Radiol. 2019 Jun 11.

54.55. Varghese B, Chen F, Hwang D, Palmer SL, De Castro Abreu AL, Ukimura O, Aron M, Aron M, Gill

Formatted: Font: Helvetica, 9 pt

Formatted: Left, Indent: Left: $1.27 \mathrm{~cm}$, Line spacing: single, No bullets or numbering 
and radiomics applied to multiparametric magnetic resonance images. Sci Rep. 2019-Feb $7: 9(1): 1570$. 